\title{
ANALISIS PENGARUH HARI LIBUR IDUL FITRI TERHADAP RETURN SAHAM DAN VOLUME PERDAGANGAN SAHAM PADA SEKTOR FOOD AND BEVERAGE DI BURSA EFEK INDONESIA TAHUN 2016-2018
}

\author{
Nining Riska Rahmawati ${ }^{1}$, Risal Rinofah ${ }^{2}$, Mujino $^{3}$ \\ ${ }^{1,2,3}$ Fakultas Ekonomi UniversitasSarjanwiyataTamansiswa \\ Email: riskharahma27@gmail.com
}

\section{Intisari}

Penelitian ini bertujuan untuk memahami dan mengkaji apakah terdapat perbedaan dari return saham dan volume perdagangan saham sebelum dan sesudah hari libur idul fitri yang terdaftar di Bursa Efek Indonesia pada tahun 2016-2018.

Populasi dari penelitian ini adalah perusahaan subsektor Food \& Beverage yang terdaftar di Bursa Efek Indonesia pada tahun 2016-2018 sebanyak 18 perusahaan. Sampel yang diambil sebanyak 11 perusahaan dengan menggunakan teknik purposive sampling. Data diperoleh melalui website Indonesian Stock Exchange (www.idx.co.id) dan Yahoo! Finance. Teknik analisis data menggunakan uji asumsi klasik dan uji beda (Paried Sample T-test) dengan alat yang digunakan adalah program SPSS.

Hasil penelitian menunjukan bahwa dari uji beda return saham sebelum dan sesudah tidak terdapat perbedaan. Dan hasil dari uji beda volume perdagangan saham tidak terdapat perbedaan pada sebelum dan sesudah hari libur idul fitri.

Kata Kunci: Hari Libur,Return Saham, Volume Perdagangan Saham

\section{Abstract}

This study aims to understand and assess whether there are differences in stock returns and trading volume before and after the Eid holiday which is listed on the Indonesia Stock Exchange in 2016-2018.

The population of this study is the Food \& Beverage sub-sector companies listed on the Indonesia Stock Exchange in 2016-2018 as many as 18 companies. Samples taken as many as 11 companies using purposive sampling technique. Data obtained through the Indonesian Stock Exchange website (www.idx.co.id) and Yahoo! Finance Data analysis techniques using the classic assumption test and the different test (Paried Sample T-test) with the tool used is the SPSS program.

The results showed that the different stock returns before and after there were no differences. And the results of the different stock trading volume test there are no differences on before and after the Eid holiday.

Keywords: Holidays, Stock Returns, Trading Volume, Stock

\section{PENDAHULUAN}

Pasar modal merupakan kegiatan ekonomi yang memungkinkan suatu perusahaan untuk memperoleh tambahan dana atau memperjual belikan surat. Disisi lain seorang investor yang membeli surat-surat berharga juga mengharapkan mendapatkan suatu return (pendapatan). Seorang investor yang cakap akan terus mempertimbangkan pergerakan dari indeks-indeks pasar guna untuk memperoleh informasi dan gambaran guna untuk memberi suatu keputusan investasi. Apakah harga-harga saham mengikuti perubahan penghasilan, perkiraan inflansi, persediaan utang, kurs, kesempatan investasi atau kombinasi dari semua tentu merupakan suatu kajian yang harus dipahami dan dimengerti oleh seorang investor.

Gejolak di pasar modal dapat berpengaruh terhadap kondisi pasar yang efsien dan mampu bergerak secara cepat terhadap informasi yang relevan dengan tolak ukur kecepatan informasi baru yang tercemin dalam suatu sekuritas. Pasar efisien akan cepat bereaksi terhadap informasi 
baru yang membentuk keseimbangan harga yang baru. Pasar dikatakan efisien apabila nilai dari suatu harga yang terbentuk di dalam pasar mencerminkan suatu informasi yang ada. Dalam realitanya sangatlah sulit untuk menemukan kondisi pasar efisien dan sempurna. Kondisi seperti itu yang menyebabkan seorang investor memperoleh return yang diinginkan. Seperti inilah yang menandai terjadinya anomali pasar. Para investor membaca anomali pasar guna untuk mengetahui pergerakan pola untuk memperoleh return.

Menurut Jogiyanto Hartono (2010), event study yaitu penelitian yang digunakan untuk menguji suatu kandungan informasi dari peristiwa dan dapat digunakan untuk menguji efisiensi pasar setengah kuat. Menurut Tandelilin (2010) Return yaitu salah satu indikator yang mempengaruhi investor untuk melakukan investasi dan juga merupakan imbalan yang diberikan kepada investor atas keberanian menanggung risiko atas investasi yang dilakukannya.

Perkembangan harga saham dan volume perdagangan saham akan memberikan informasi bagi investor untuk mengetahui pasar, di mana pada saat volume perdagangan saham dalam jumlah yang kecil dapat menyebabkan kenaikan harga (Darwis, 2012). Penelitian Titik Hinarwati (2016) dalam penelitian ini mempelajari apakah terjadi perbedaan antara sebelum dan sesudah hari raya idul fitri terhadap abnormal return. Berdasarkan hasil penelitian Samhaji, Moh Amin, Junaidi (2018) ini tidak adanya perbedaan pada saat sebelum dan sesudah hari libur keagamaan terhadap abnormal return dan aktivitas volume tranding.

\section{KAJIAN PUSTAKA DAN PENGEMBANGAN HIPOTESIS Pasar Modal}

Pasar modal merupakan suatu kondisi yang mempertemukan antara penjual dengan pembeli dana. Dana yang digunakan untuk jual beli tersebut digunakan dalam jangka waktu yang lama dengan tujuan untuk menunjang pengembangan suatu organisasi atau perusahaan. Kegiatan jual beli dilakukan oleh suatu lembaga resmi yang sering disebut dengan Bursa Efek Indonesia

\section{Idul Fitri Effect}

Menurut Utomo dan Herlambang (2015) Idul Fitri effect ialah salah satu hari libur nasional yang ada di Indonesia yang cenderung lama dibanding hari libur lain sehingga aktivitas perdagangan saham di bursa efek berhenti cukup lama maka dari itu terdapat kecenderungan bahwa return saham sebelum libur dan setelah libur akan mengalami harga yang lebih tinggi dibandingkan return saham hari biasa

\section{Return Saham dan Abnormal Return}

Return adalah imbalan yang diperoleh seorang investor dari kepemilikan atas keberanian menanggung risiko investasi yang dilakukan terdiri dari dividen dan capital gain/loss Abnormal return adalah return yang diperoleh seorang investor yang tidak sesuai dengan apa yang diharapkan.

\section{Volume Perdagangan Saham}

Volume perdagangan saham merupakan jumlah lembar saham yang diperdagangkan secara harian. Sedangkan volume perdagangan adalah jumlah lembar saham suatu perusahaan yang diperdagangkan dalam waktu tertentu.

\section{Bursa Efek Indonesia}

Bursa Efek Indonesia adalah suatu bursa saham yang dapat memberikan peluang investasi kepada seluruh investor dan sumber pembiayaan dalam upaya mendukung pembangunan ekonomi. Bursa Efek Indonesia juga berperan dalam upaya mengembangkan pemodalan lokal yang besar untuk menciptakan pasar yang stabil.

\section{Penelitian terdahulu}

Berbagai penelitian yang terkait dalam judul diatas dengan pengungkapan pengaruh hari libur idul fitri terhadap return saham dan volume perdagangan menunjukan hasil yang 
berbeda-beda. Penelitian Uli Latifah (2012) Hasil dari penelitian ini menunjukan bahwa terdapat adanya perbedaan sebelum dan sesudah hari libur keagamaan. Namun pada saat setelah hari libur akan mengalami peningkatan terhadap return saham.

Penelitian Titik Hinarwati (2016) dalam penelitian ini bertujuan mengetahui sebelum dan sesudah pengaruh hari libur idul fitri terhadap abnormal return. Hasil penelitian sebelum dan sesudah hari raya idul fitri menunjukan tidak signifikan. Penelitian Samhaji, Moh Amin, Junaidi (2018) Hasil penelitian ini menunjukan bahwatidak terdapat perbedaan sebelum dan sesudah hari libur keagamaan terhadap abnormal return dan tranding volume activity. Penelitian Utomo dan Herlambang (2015) hasil penelitian ini menunjukan bahwa terdapat adanya perbedaan yang signifikan antara tranding volume activity sebelum dan sesudah adanya peristiwa hari raya idul fitri. Hal ini dapat diartikan bahwa dengan adanya peristiwa hari libur Idul Fitri dapat memberikan sinyal positif bagi investor dalam mengambil keputusan investasi dan mampu meningkatkan permintaan yang dapat menimbulkan perubahan volume perdagangan. Anggraini (2017) Hasil dari penelitian ini menunjukan bahwa tidak ada perbedaan abnormal return dan trading volume activity sebelum dan sesudah libur idul fitri. Penelitian Khaled, Sada (2018) Hasil dari penelitian ini menemukan perubahan yang signifikan dalam indeks TASI selama bulan Ramadhan dan Ashoura dan tidak ada perubahan yang signifikanpada periode selama haji, dalam hal volume terdapat perubahan yang signifikan selama bulan Ramadhan

\section{Pengembangan Hipotesis}

\section{Pengaruh Hari Libur Idul Fitri terhadap Return Saham}

Ramadhan merupakan salah satu tradisi keagamaan yang terkenal di dunia. Ramadhan merupakan suatu peristiwa perayaan bagi umat muslim yang dirayakan rutin setiap tahunnya. Bulan ramadhan juga indentik dengan meningkatnya pola konsumsi masyarakat. Bagi pelaku pasar modal peningkatan pola konsumsi masyarakat selama bulan Ramadhan membuat sahamsaham khususnya di sektor minuman dan makanan akan mengalami peningkatan penjualan.

Uli Latifah (2012) menemukan bahwa pada hari libur keagamaan lebih berpengaruh terhadap return saham di karenakan pada saat hari libur keagamaan masyarakat akan lebih banyak membelanjakan uangnya untuk memenuhi kebutuhan menjelang hari raya idul fitri. Dan pada saat sesudah hari libur maka masyarakat akan menginvestasikan kembali uangnnya.

H1: terdapat perbedaan return saham sebelum dan sesudah hari raya idul fitri

\section{Pengaruh Hari Libur Idul Fitri terhadap Volume Perdagangan Saham}

Pada saat menjelang hari raya idul fitri salah satu perusahaan akan mengalami peningkatan adalah perusahaan yang bergerak di bidang minuman dan makanan karena merupakan kebutuhan primer bagi masyarakat. Meninggkatnya konsumsi masyarakat di bulan Ramadhan akan mengakibatkan permintaan produk minuman dan makanan juga akan meningkat sehingga data penjualan juga akan meningkat. Peningkatan tersebut membuat investor dapat menilai suatu perusahaan itu bekerja dengan baik. Hal ini akan menjadikan daya tarik untuk investor agar menanamkan modalnya di dalam perusahaan tersebut. Maka akan banyak investor yang tertarik untuk membuat permintaan saham. Peningkatan permintaan saham ini akan berpengaruh pada meningkatnya volume perdagangan saham. Namun peningkatan volume perdagangan pada saat bulan Ramadhan akan mengalami penurunan seiring dengan berakhirnya bulan ramadhan.

Hasil penelitian yang dilakukan oleh Utomo dan Herlambang (2015) yang menyatakan bahwa terdapat perbedaan yang signifikan antara tranding volume activity sebelum dan sesudah adanya peristiwa hari raya idul fitri. Hal ini dapat diartikan bahwa dengan adanya peristiwa hari libur Idul Fitri memberikan sinyal positif bagi investor dalam mengambil keputusan investasi sehingga meningkatkan permintaan yang dapat menimbulkan perubahan volume perdagangan. 
H2: terdapat perbedaan volume perdagangan saham sebelum dan sesudah adanya peristiwa hari raya idul fitri.

Berdasarkan uraian diatas maka hipotesis yang diuji yaitu sebagai berikut:

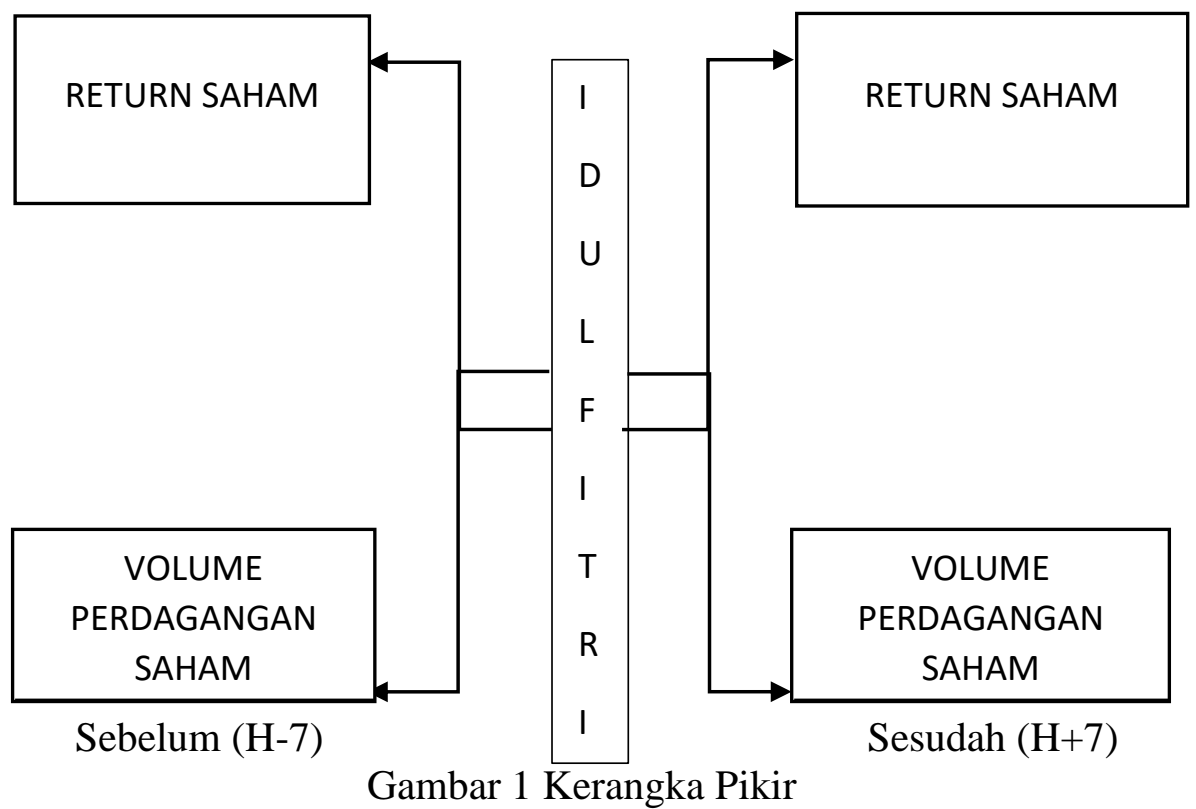

\section{METODE PENELITIAN \\ Sifat Penelitian}

Penelitian ini hanya untuk menunjukan terdapat perbedaan atau tidak pengaruh hari libur idul fitri terhadap return saham dan volume perdagangan saham pada perushaan sub sector Food \& Beverage yang terdaftar di Bursa Efek Indonesia pada tahun 2016-2018.

\section{Variabel Penelitian}

Tabel 1. Definisi Operasional Variabel

\begin{tabular}{c|l}
\hline Variabel & \multicolumn{1}{c}{ Indikator } \\
\hline Return Saham & $\begin{array}{l}\mathrm{AR}_{\mathrm{i}, \mathrm{t}}=\mathrm{R}_{\mathrm{i}, \mathrm{t}}-\mathrm{R}_{\mathrm{mi}, \mathrm{t}} \\
\underline{\mathrm{IHSG}}_{\mathrm{m}, \mathrm{t}-\mathrm{IHSG}_{\mathrm{m}, \mathrm{t}-1}}^{\mathrm{IHSG}}\end{array}$ \\
\hline $\begin{array}{c}\text { Volume Perdagangan } \\
\text { Saham }\end{array}$ & $\mathrm{TVA}=\frac{\text { Jumlah Saham yang Diperdagangkan }}{\mathrm{Jumlah} \text { Saham yang Beredar }}$ \\
\hline
\end{tabular}

\section{Populasi, Sampel dan Teknik PengambilanSampel}

Populasi yang digunakan dalam penelitian ini adalah18 perusahaan Food \& Beverage yang terdaftar di Bursa Efek Indonesia. Sampel yang digunakan menggunakan data 11 perusahaan dalam 3 periode dari tahun 2016-2018 yang memenuhi kriteria dalam penelitian ini. Metode dalam penelitian ini menggunakan purposive sampling dengan ciri-ciri khusus sesuai dengan tujuan dalam penelitian ini.

\section{Tabel 2 Karakteristik Sampel}

\begin{tabular}{ll}
\hline NO & \multicolumn{1}{c}{ Karakteristik } \\
\hline 1. & Perusahaan makanan dan minuman yang terdaftra di Bursa Efek Indonesia tahun 2016-2018 \\
2. & Perusahaan yang aktif melakukan aktivitas perdagangan saham selama periode penelitian \\
3. & Data yang dibutuhkan tersedia secara lengkap \\
\hline
\end{tabular}


HASIL DAN PEMBAHASAN

Deskripsi Data

Tabel 3

Hasil Uji Statistik Data Deskriptif

\begin{tabular}{llll}
\hline & $\mathrm{N}$ & Mean & Std. Deviation \\
\hline Abnormal Sebelum & 7 & -.0029729 & .00433569 \\
Abnormal Sesudah & 7 & -.0082014 & .00568719 \\
Volume Sebelum & 7 & .0015729 & .00097240 \\
Volume Sesudah & 7 & .0027214 & .00257228 \\
\hline
\end{tabular}

Sumber : Data Statistik Diolah dengan SPSS 18

\section{Pengujian Asumsi Klasik}

Tabel 4 Uji Normalitas

One-Sample Kolmogorov-Smirnov Test

\begin{tabular}{lll}
\hline & Sig. & Ket. \\
\hline Abnormal Sebelum & .991 & Normal \\
Abnormal Sesudah & .963 & Normal \\
\hline
\end{tabular}

Sumber : Data StatistikDiolahdengan SPSS 18

Berdasarkan hasil output pada table 5 menujukan bahwa tingkat signifikasi abnormal return saham yang signifikan adalah .991 dan .963 yang berarti lebih besar dari nilai signifikansi sebesar 0.05. hasil ini menunjukan bahwa data terdistribusi normal

Tabel 5 Uji Normalitas

One - Sample Kolmogorov - Smirnov Test

\begin{tabular}{lll}
\hline & Sig. & Ket. \\
\hline Volume Sebelum & .500 & Normal \\
Volume Sesudah & .457 & Normal \\
\hline Sumber: Data Statistik & Diolah dengan SPSS 18
\end{tabular}

Sumber: Data Statistik Diolah dengan SPSS 18

Berdasarkan hasil output tabel 6 menunjukan bahwa tingkat signifikasi abnormal return saham yang signifikan adalah .500 dan .457 yang berarti lebih tinggi dari nilai signifikansi sebesar 0.05. hasil ini menunjukan bahwa data terdistribusi normal.

\section{UJI HIPOTESIS}

\begin{tabular}{|c|c|c|c|}
\hline \multicolumn{4}{|c|}{$\begin{array}{c}\text { Tabel } 6 \text { Hasil Uji Beda } \\
\text { Paried Sample Test }\end{array}$} \\
\hline & $\mathrm{T}$ & $\begin{array}{l}\text { Sig. } \\
\text { tailed })\end{array}$ & Keterangan \\
\hline $\begin{array}{l}\text { Abnormal Sebelum- } \\
\text { Abnormal Sesudah }\end{array}$ & 2,372 & ,055 & $\begin{array}{l}\text { Tidak terbukti atau tidak terdapat } \\
\text { perbedaan }\end{array}$ \\
\hline
\end{tabular}

Sumber: Data Statistik Diolah dengan SPSS 18

Dari hasil pengujian perbandingan return saham pada periode sebelum dan sesudah hari libur idul fitri, diperoleh nilai t hitung sebesar 2,372 dan signifikansi sebesar ,055.berdasarakan hasil output pada tabel 6 dapat dilihat bahwa sig. ,055> dari tingkat signifikansi 0,05. Dapat disimpulkan bahwa tidak adanya perbedaan return saham yang signifikan pada periode sebelum dan sesudah hari libur idul fitri. 
Tabel 7 Hasil Uji Beda

Paried Sample Test

\begin{tabular}{llll}
\hline \multicolumn{5}{c}{ T } & Sig. (2-tailed) & Keterangan & \\
\hline $\begin{array}{l}\text { Volume } \\
\text { Volume Sesudah }\end{array}$ & $-1,050$ &, 334 & $\begin{array}{l}\text { Tidak terbukti atau tidak ada } \\
\text { perbedaan }\end{array}$ \\
\hline
\end{tabular}

Sumber: Data Statistik Diolah dengan SPSS 18

Dari hasil perbandingan volume perdagangan saham pada periode sebelum dan sesudah hari libur idul fitri, diperoleh nilai t hitung sebesar -1,050 dan signifikansi ,334. Berdasarkan hasil output pada tabel 7 dapat dilihat bahwa nilai sig. ,334> dari tingkat signifikansi 0,05. Hal ini menunjukan bahwa tidak adanya perbedaan volume perdagangan saham yang signifikansi pada periode sebelum dan sesudah hari libur idul fitri, artinya hipotesis ke dua terbukti.

\section{PEMBAHASAN}

\section{Pengaruh Hari Libur Idul Fitri terhadap Return Saham}

Hipotesis pertama dalam penelitian ini menyatakan bahwa terdapat perbedaan return saham antara sebelum dan sesudah hari libur Idul Fitri. Tetapi dari hasil pengujian menunjukan bahwa tidak terdapat perbedaan return saham sebelum dan sesudah hari libur Idul Fitri. Sehingga hipotesis yang menyatakan bahwa terdapat perbedaan return saham sebelum dan sesudah hari libur Idul Fitri tidak terbukti.

Hal ini menyebabkan tidak adanya pengaruh sebelum dan sesudah hari libur Idul Fitri terhadap abnormal return yang disebabkan oleh pelaku investor yang mempunyai sikap individual dalam mengambi keputusan, dan tidak mempertimbangkan yang akan terjadi dan hanya berpedoman pada objek

\section{Pengaruh Hari Libur Idul Fitri terhadap Volume Perdangan Saham}

Hipotesis kedua dalam penelitian ini menyatakan bahwa terdapat perbedaan volume perdagangan saham sebelum dan sesudah hari libur Idul Fitri. Tetapi dari hasil pengujian yang menunjukan bahwa tidak terdapat perbedaan volume perdagangan saham sebelum dan sesudah hari libur Idul Fitri. Sehingga hipotesis yang menyatakan bahwa terdapat perbedaan volume perdagangan saham sebelum dan sesudah hari libur Idul Fitri tidak terbukti.

Informasi Idul Fitri yang di dapat oleh seorang investor dianggap tidak menarik karena tidak adanya reaksi pasar yang signifikan pada periode sesudah pengumuman Idul Fitri yang artinya bahwa investor di Indonesia masih belum mengantisipasi secara cepat informasi yang diterimanya di pasar modal atau investor menganggap bukan sebagai good news dan memilih untuk menunda rencana investasi sambil menunggu perkembangan saham selanjutnya. Investor terlebih dahulu menganalisis fenomena ini dan tidak terburu-buru mengambil tindakan, karena ternyata meningkatnya volume perdagangan saham perusahaan makanan dan minuman ini tidak lebih dari sensasi. Namun pada kenyataanya investor akan kembali berinvestasi setelah hari Libur Idul Fitri.

\section{PENUTUP}

\section{Kesimpulan}

Dari hasil uji beda return saham pada periode sebelum dan sesudah hari libur idul fitri diketahui bahwa nilai sig. 0,055 lebih besar dari tingkat signifikansi 0,05 yang artinya bahwa hipotesis pertama tidak terbukti. Dari hasil uji beda volume perdagangan saham sebelum dan sesudah hari libur Idul Fitri diketahui bahwa nilai sig. 0,334 lebih besar dari tingkat signifikansi 0,05 yang artinya bahwa hipotesis kedua terbukti. 


\section{Saran}

Berdasarkan kesimpulan dan keterbatasan penelitian yang ada, terdapat beberapa saran agar penelitian selanjutnya mengenai hari libur Idul fitri Lebih sempurna. Adapun saran bagi peneliti selanjutnya yaitu variable yang diteliti dapat ditambah sehingga diharapkan dapat menggabarkan pengaruh hari libur secara lebih akurat dan sampel yang digunakan ditambah atau diganti pada sektor manufaktur yang lain.

\section{DAFTAR PUSTAKA}

Anggraini, M. C. (2017). Jurnal Analisis Perbandingan Return Dan Trading Volume Activity Sebelum Dan Sesudah Idul Fitri Pada Perusahaan Makanan Dan Minuman Yang Listing Di Bursa Efek Indonesia Periode 2014-2016. Simki-Economic, 01(2), 1-13.

Darwis. (2012). Pengaruh Volume Perdagangan Terhadap Return Saham LQ- 45 Selama Bulan Ramadhan Di Bei. 1-6.

Hinawati, T. (2016). Efek Hari Libur Idul Fitri Terhadap Abnormal Return Saham Di Bursa Efek Indonesia. Cakrawala, Xi(1), 34-50.

Jogiyanto Hartono, Teori Portofolio Dan Analisis Investasi, Edisi Ketujuh , Bpfe, Yogyakarta, 2010, Hlm.555-556

Khaled, S., \& Saud, A. (2018). Islamic Calendar Effect On The Saudi Stock Market ( Tasi ). Multi-Knowledge Electronic Comprehensive Journal For Education And Science Publications (Mecsj), (14), 1-26.

Samhaji, Amin, M., \& Junaidi. (2018). Pengaruh Hari Libur Keagamaan Terhadap Return Saham Dan Tranding Volume Activity (Tva) (Study Pada Saham Yang Terdaftar Dalam Kelompok Perusahaan LQ45). E-Jra Fakultas Ekonomi Dan Bisnis Universitas Islam Malang, 07(06), 42-49.

Tandelilin, E. (2010). Portofolio Dan Investasi Teori Dan Aplikasi. In Kanisius.

Uli Latifah. (2012). Analisis Perbedaan Return Saham Sebelum Dan Sesudah Hari Libur Keagamaan Serta Hari Libur Nasional.

Utomo, V. J., \& Herlambang, L. (2015). Efek Hari Libur Lebaran Pada Emiten Yang Terdaftar Dalam Issi Periode 2011-2013. Journal Of Chemical Information And Modeling, 2(5), 2 15. Https://Doi.Org/10.1017/Cbo9781107415324.004

www.finance.yahoo.com

www.idx.co.id 